\title{
A five-year review of childhood mortality at the University College Hospital, Ibadan
}

\author{
*O.O. Ayoola, A. E. Orimadegun, A. K. Akinsola and K. Ósinusi \\ Department of Paediatrics \\ University College Hospital \\ PMB 5116, lbadan \\ E-mail: ooayoola@yahoo.com
}

\begin{abstract}
Summary
Introduction:The present study sought to provide a comprehensive description of causes of mortality in a local Nigerian children population as a measure of their health status.

Methods and patients: A retrospective study of the pattern of mortality among 12,522 children admitted into all the six wards of the department of Paediatrics, University College Hospital, Ibadan during a five-year period (January 1996 - December 2000) was done.

Results: There were 1,185 deaths with an overall mortality rate of 9.5 per cent. There was no significant change in childhood mortality rate over the five years reviewed. Of the 1185 deaths, $48.8 \%$ occurred within 24 hours and neonatal deaths accounted for $50.8 \%$ of the total number of deaths. The leading causes of death were neonatal tetanus, Prematurity/low birth weight, neonatal septicaemia, severe birth asphyxia, meningitis, severe malaria, pneumonia, septicaemia, severe malnutrition, and measles. Deaths from sickle cell anaemia were found only among children above 5 years of age.

Conclusions: Majority of deaths occurred in neonates and were preventable.
\end{abstract}

Key-words: Mortality, Neonates, Infants, Under-5.

\section{Résumé}

Introduction: L'objet de cette étude est de donner une description détaillée des causes de mortalité chez la population rurales des enfants nigerians comme la mesure pour le statut de leur santé.

Méthodes et patients: Une étude rétrospective de la tendance de mortalité chez 12,522 enfants admis dans tous les six salles du département de pédiatric collége hospitalier universitaire, Ibadan pendant une période de cinq ans (janvier 1996 décembre 2000) a été effectuée.

Resultat: Il y avaient 1,185 morts avec un taux de rendement total de mortalité de $9,5 \%$ il n'y avait aucun changement sensible dans le taux de mortalité d'enfance au cours de bilan de 5 ans d'étude. Entre 1,185 morts, $48.8 \%$ a eu lieu en moins de 24 heures et morts néonataux constituent $50,8 \%$ de rendement total des morts. Les causes principals des morts étaient tétanos néonatal, poid de naissance bas/prématuré, septicemie neonatale sous alimentation grave, et la rougeole. Morts attribuables à la drépanocytose sont trouvées seulement chez des enfants âgés de plus de 5 ans.

Conclusion: Le grand nombre des morts arrivait chez les néonates sont évitables.

\section{Introduction}

More than 10 million children die every year from preventable causes, almost all in developing countries. Ninety percent of these deaths occur in just 42 countries'. According to WHO figures, the world's average child mortality rate in the year 2000 was 67 per 1000 live births with marked improvement from 85 per 1000 in $1990 .{ }^{2}$ But in Africa, the child mortality rates are averagely 150 per 1000 live births, which is 8 times that seen in Europe. ${ }^{2}$ In 7 African countries, there has been little or no change in child mortality rate over the past 50 years. ${ }^{3}$

Currently, infant and under-5 mortality rate in Nigeria are estimated as 110 per 1000 and 183 per 1000 respectively. ${ }^{4}$ In Nigeria and many developing countries, due to various constraints in community based research, hospital records of morbidity and mortality rates are still the basis of many published health statistics. ${ }^{5}$ In spite of their limitations, these set of data are significant pointers to disease pattern in the community. ${ }^{6}$

Three previous studies carried out at the University College Hospital (UCH) Ibadan have examined pattern of paediatric deaths. ${ }^{7-9}$ Hendrickse ${ }^{7}$ and Adeyokunnu et al. ${ }^{8}$ examined the pattern of deaths in all the paediatric wards in the hospital while Bamgboye and Familusi ${ }^{9}$ reviewed mortality pattern at the emergency ward only. The two earlier studies covered the periods, 1964-1966 and 19691973 respectively while the latter included 1978,1981 1986. The purpose of this study is to review the current pattern of childhood mortality in UCH, Ibadan, Nigeria.

\section{Methodology}

The Paediatrics Department of the University College Hospital (UCH), Ibadan serves as a tertiary referral centre for all health centres in Ibadan and other parts of Nigeria. The department comprises of six wards with one hundred and fifty-eight beds.

The case records of all patients presenting from 1996 to 2000 were examined retrospectively to document the total number of admissions and all deaths that occurred on the wards. The information extracted from these records included age at admission, the gender, causes of death, 
place of referral, duration of admission and date of death. The extracted data were entered into structured questionnaires, checked and corrected for errors; they were entered into computer and analyzed using the SPSS 11 software for windows package for data entries, frequencies and cross tabulations. All data, which were either not available or unknown on any item during crosstabulations, were excluded from the denominator of the rates calculated.

\section{Results}

During the five-year period, a total of 12,522 children were admitted into the department out of which were a total of 1,341 deaths. Out of the 1,341 deaths, 156 were

Table 1 Yearly distribution of childhood deaths at UCH Ibadan, 1996-2000

\begin{tabular}{lccc}
\hline Year & $\begin{array}{l}\text { Total number } \\
\text { admissions } \\
\text { (\% of total) }\end{array}$ & $\begin{array}{l}\text { Number of } \\
\text { deaths }\end{array}$ & $\begin{array}{l}\text { Death rate } \\
(\%)\end{array}$ \\
1996 & $1910(15.3)$ & 132 & 6.9 \\
1997 & $2263(18.1)$ & 267 & 11.8 \\
1998 & $3528(28.2)$ & 224 & 6.4 \\
1999 & $2486(19.9)$ & 293 & 11.8 \\
2000 & $2335(18.5)$ & 269 & 11.5 \\
Total & $12522(100)$ & 1185 & 9.5 \\
\hline
\end{tabular}

Table 2 Proportional death rate of children by month over the five year period - 1996-2000.

\begin{tabular}{lcc}
\hline & Frequency & Percent \\
Month & 94 & 7.9 \\
January & 76 & 6.4 \\
February & 123 & 10.4 \\
March & 110 & 9.3 \\
April & 74 & 6.2 \\
May & 78 & 6.6 \\
June & 127 & 10.7 \\
July & 148 & 12.5 \\
August & 74 & 6.2 \\
September & 93 & 7.8 \\
October & 98 & 8.3 \\
November & 90 & 7.6 \\
December & 1185 & 100.0 \\
Total & & \\
\end{tabular}

Table 3 The age group and sex distribution of deaths

\begin{tabular}{|c|c|c|c|}
\hline & Deaths & & Total \\
\hline Age & Male & Female & n (\%) \\
\hline 0.28 days & 330 & 287 & $617(52.1)$ \\
\hline 29 days-1 year & 107 & 93 & $199(16.8)$ \\
\hline$>$ 1year-5years & 138 & 106 & $244(20.6)$ \\
\hline Over 5 years & 86 & 39 & $125(10.5)$ \\
\hline Total & 661 & 524 & 1185 \\
\hline $\mathrm{n}(\%)$ & $(55.8)$ & $(44.2)$ & $(100)$ \\
\hline
\end{tabular}

WAJM VOL. 24 NO. 2, APRIL-JUNE, 2005
Table 4 Principal causes of deaths in all age groups

\begin{tabular}{lcc}
\hline Causes of death & Number of cases & $\%$ \\
Neonatal tetanus & 163 & 13.8 \\
Prematurity and Low birth weight & 136 & 11.5 \\
Neonatal Septicaemia & 124 & 10.5 \\
Scvere birth asphyxia & 124 & 10.5 \\
Meningitis & 87 & 7.3 \\
Severe Malaria & 73 & 6.2 \\
Pneumonia & 56 & 4.7 \\
Septicacmia & 55 & 4.6 \\
Severe malnutrition & 52 & 4.4 \\
Measles & 42 & 3.5 \\
Malignancies & 41 & 3.5 \\
Gastroenteritis & 31 & 2.6 \\
Severe anaemia & 29 & 2.4 \\
Tuberculosis & 28 & 2.4 \\
Neonatal Jaundice & 26 & 2.2 \\
Sickle Cell anaemia & 26 & 2.2 \\
Renal diseases & 13 & 1.1 \\
Congenital malformation & 12 & 1.0 \\
Hepatitis & 11 & .9 \\
Congenital Heart disease & 10 & .8 \\
Post neonatal tetanus & 10 & .8 \\
Burns & 7 & .6 \\
Acquire heart disease & 6 & .5 \\
Infantile cholestasis & 5 & .4 \\
HIV/AIDS & 4 & .3 \\
Other Neuologic infection & 3 & .3 \\
Metabolic disorder & 3 & .3 \\
Rabies & 2 & .2 \\
Kerosene poisoning & 2 & .2 \\
Drug reactions & 2 & .2 \\
Unknown/Brought in dead & 1 & .1 \\
Pyomyositis & 1 & 100.0 \\
Total & & \\
\hline & & \\
& &
\end{tabular}

excluded from further analysis due to incomplete information with regard to date of death and cause of death so 1,185 had acceptable data for this study resulting in overall mortality rate of 9.5 percent. The mean age was 18.4 months with the oldest child being $17 y$ ears. There were 661 males and 524 females, with a M: Fratio of 1.3:1.

The annual admission pattern and proportional death rates for each year is as shown in Table 1. The highest number of admissions was recorded in 1998 while

Table 5 Causes of deaths among the neonates

\begin{tabular}{lcc}
\hline Causes of death & Number of cases & \multicolumn{1}{c}{$\%$} \\
Neonatal tetanus & 163 & 26.4 \\
Prematurity/Low birth weight & 136 & 22.0 \\
Neonatal Septicaemia & 124 & 20.1 \\
Severe birth asphyxia & 123 & 19.9 \\
Meningitis & 26 & 4.2 \\
Neonatal Jaundice & 26 & 4.2 \\
Congenital malformation & 12 & 1.9 \\
Congenital Heart disease & 4 & .6 \\
Pneumonia & 2 & .3 \\
Metabolic disorder & 1 & .2 \\
Total & 617 & 100.0 \\
\hline
\end{tabular}


Table 6 Causes of deaths among age 29 days-1 year

\begin{tabular}{lcc}
\hline Causes of death & Number of cases & $\%$ \\
Septicaemia & 32 & 16.1 \\
Severe Malaria & 26 & 13.1 \\
Pneumonia & 25 & 12.6 \\
Meningitis & 23 & 11.6 \\
Severe malnutrition & 21 & 10.6 \\
Gastroenteritis & 18 & 9.0 \\
Measles & 15 & 7.5 \\
Severe anaemia & 7 & 3.5 \\
Tuberculosis & 7 & 3.5 \\
Malignancies & 6 & 3.0 \\
Infantile cholestasis & 5 & 2.5 \\
Sickle Cell anaemia & 3 & 1.5 \\
Post neonatal tetanus & 3 & 1.5 \\
Renal diseases & 2 & 1.0 \\
Hepatitis & 2 & 1.0 \\
HIV/AIDS & 1 & .5 \\
Unknown/Brought in dead & 1 & .5 \\
Congenital Heart disease & 1 & .5 \\
Metabolic disorder & 1 & .5 \\
Total & 199 & 100.0 \\
\hline
\end{tabular}

1996 had the lowest record. The yearly mortality rates ranged from $6.4 \%$ to $11.8 \%$.

The number of deaths for each month of the years in review is shown in Table 2. The highest number of deaths was recorded in the months of August (12.5\%), July (10.7\%) and March (10.4\%) while the least number of deaths were recorded in May (6.2\%) and September (6.2\%)

In $88(7.4 \%)$ of these deaths the ante-mortem diagnoses were complemented with findings at autopsy (autopsy ratio 1:12.4). Five hundred and seventy-nine (48.8\%) of the deaths occurred within 24 hours of admission, while 370 (31.2\%) occurred within 3-7 days of admission. Only 236 deaths (20.0\%) occurred after a week of admission. The age group and sex distribution of deaths

Table 7 Causes of deaths among age 1-5years

\begin{tabular}{lcc}
\hline Causes of death & Number of cases & $\%$ \\
Severe Malaria & 32 & 13.1 \\
Severe malnutrition & 31 & 12.7 \\
Meningitis & 29 & 11.9 \\
Measles & 27 & 11.1 \\
Pneumonia & 22 & 9.0 \\
Severe anaemia & 17 & 7.0 \\
Malignancies & 15 & 6.1 \\
Septicaemia & 12 & 4.9 \\
Gastroenteritis & 11 & 4.5 \\
Tuberculosis & 10 & 4.1 \\
Sickle Cell anaemia & 10 & 4.1 \\
Hepatitis & 7 & 2.9 \\
Congenital Heart disease & 4 & 1.6 \\
Post neonatal tetanus & 4 & 1.6 \\
Burns & 2 & .8 \\
Renal diseases & 2 & .8 \\
Other Neuologic infection & 2 & .8 \\
Kerosene poisoning & 2 & .8 \\
Drug reactions & 2 & .8 \\
HIV/AIDS & 1 & .4 \\
Acquire heart disease & 1 & .4 \\
Pyomyositis & 1 & .4 \\
Total & 244 & 100.0 \\
\hline
\end{tabular}

are shown in Table 3. Six hundred and seventeen (51.8\%) of the total deaths occurred in neonates, $232(19.7 \%)$ occurred in older infants (29 days -1 year), $200(16.9 \%)$ deaths were in children aged greater than 1 to 5 years, while $137(11.6 \%)$ were in the age group older than 5 years. There was a progressive decline in the numbers of deaths as the ages increased.

\section{Causes of death}

The disease entities identified among the 1185 deaths are listed in order of their prevalence in Table 4. Most common causes of deaths were neonatal tetanus $163(13.8 \%)$, prematurity/low birth weight $136(11.5 \%)$, neonatal septicaemia $124(10.5 \%)$, severe birth asphyxia $124(10.5 \%)$, meningitis $87(7.3 \%)$, severe malaria 73 (6.2\%), pneumonia $56(4.7 \%)$ and septicaemia $55(4.6 \%)$. Least among identified causes of deaths were rabies and kerosene poisoning.

There were significant differences in the leading causes of death in the different age groups as shown in tables 5 to 8 . The principal causes of death among the neonates were neonatal tetanus $163(26.4 \%)$, prematurity/ low birth weight $136(22.0 \%)$, neonatal septicaemia 124 (20.1\%), severe birth asphyxia $123(19.9 \%)$, meningitis 26 (4.2\%) and neonatal jaundice $26(4.2 \%)$ (Table 5). Septicaemia $(16.1 \%)$ was the leading cause of death among the infants beyond the neonatal age group; this

Table 8 Causes of deaths among age above 5years

\begin{tabular}{lcc}
\hline Causes of death & Number of cases & $\%$ \\
Malignancies & 20 & 16.0 \\
Severe Malaria & 15 & 12.0 \\
Sickle Cell anaemia & 13 & 10.4 \\
Septicaemia & 12 & 9.6 \\
Tuberculosis & 11 & 8.8 \\
Meningitis & 9 & 7.2 \\
Renal diseases & 9 & 7.2 \\
Pneumonia & 7 & 5.6 \\
Severe anaemia & 5 & 4.0 \\
Burns & 5 & 4.0 \\
Acquired heart disease & 5 & 4.0 \\
Post neonatal tetanus & 3 & 2.4 \\
Gastroenteritis & 2 & 1.6 \\
HIV/AIDS & 2 & 1.6 \\
Rabies & 2 & 1.6 \\
Hepatitis & 2 & 1.6 \\
Congenital Heart disease & 1 & .8 \\
Other Neurologic infections & 1 & .8 \\
Metabolic disorder & 1 & .8 \\
Total & 125 & 100.0 \\
\hline
\end{tabular}

was closely followed by severe malaria (13.1\%), (Table 6). However, among the age group 1-5years (Table 7), severe malaria (13.1\%) severe malnutrition (12.7\%) and meningitis (11.9\%) were the three leading causes of deaths. Among the children above 5years (Table 8), malignancies (16.0\%), severe malaria (12.0\%) and sickle cell anaemia $(10.4 \%)$ were the three leading causes of deaths. 
Table 9 Distribution of deaths from different referring centres

\begin{tabular}{lcr}
\hline Referring centre & Number of cases & Percent \\
General hospitals & 560 & 47.3 \\
No referral & 300 & 25.2 \\
Private hospitals & 220 & 18.6 \\
UCH outpatient clinics & 60 & 5.1 \\
Primary hcalth centres & 25 & 2.1 \\
Other Tertiary health centres & 20 & 1.7 \\
Total & 1185 & 100.0 \\
\hline
\end{tabular}

Five hundred and sixty (47.3\%) of the all deaths were referred from general hospitals, $300(25.2 \%)$ were admitted without referral notes, 220 (18.6\%) came from private hospitals and $60(5.1 \%)$ were from other departments of the hospital (Table 9). The highest number of deaths, $690(58.2 \%)$ occurred in the emergency ward which had the highest number of admissions over the five-year period, while the least number of deaths occurred in North West 2 ward (3.1\%), which also had the lowest number of admissions over the five-year period.

Out of the six childhood vaccine-preventable diseases, neonatal tetanus for which there were 163 cases over this time period has the highest case fatality of $13.8 \%$. Others are measles (3.5\%) and tuberculosis (2.4\%).

\section{Discussion}

In Africa, it has been hard to establish the causes of deaths at community level where the majority take place. ${ }^{15}$ Therefore hospital based data despite their inadequacies, are useful indicators of the community health status and particularly of childhood population..$^{16}$ Teaching hospitals are expected to provide mainly tertiary service however, the UCH Ibadan offers primary to tertiary care without discrimination. Therefore the diversity of cases seen is representative of paediatric cases in the community.

This present study has shown an overall mortality rate of $9.5 \%$. This is an improvement compared with $14 \%$ and $13 \%$ obtained previously in similar studies carried out in the same department by Hendrickse ${ }^{4}$ and Adeyokunnu et al ${ }^{5}$ respectively more than 2 decades ago and reports from Congo ${ }^{16}$ It is also comparable to an overall mortality of $11.6 \%$ reported from University of Ilorin teaching hospital in 1987 but higher than reports from Benin. ${ }^{17}$ This may be explained by improved infrastructure in the hospital compared with earlier years. There is also a reduction in the incidence and deaths from diarrhoeal diseases due to effectiveness of preventive programmes like Control of Diarrhoeal diseases and the Integrated Management of Childhood Illnesses. There is improved health awareness and health education.

The finding of higher death proportion among male children has been reported earlier. ${ }^{8,10-11}$ The low level of awareness on the benefit and importance of post mortem examination may be part of the reasons for the low autopsy rate $(7.4 \%)$ obtained in this study. Children who died within 24 hours of admission accounted for $48.8 \%$ of the total deaths. This compares with $50 \%$ reported by Morley ${ }^{12}$ and $32.8 \%$ reported by Fagbule et al. ${ }^{11}$ The fact that neonatal deaths contributed more than half of the paediatric mortality in the hospital was earlier reported by Fagbule et al ${ }^{11}$ and Akindele et al. ${ }^{13}$

The finding of neonatal tetanus as the most common cause of deaths in the neonates was in contrast with earlier reports ${ }^{7-8,13}$ in which low birth weight and prematurity were responsible for most of the deaths in the neonatal age group. Although its death toll has reduced by a third in the last decade worldwide, there is a noticeable upsurge up to $62 \%$ in Nigeria. ${ }^{18-19}$ Major risk factors identified to be associated with this surge are incomplete or no maternal tetanus immunisation, lack of paternal education, delivery outside health facility, untrained personnel at delivery, use of contaminated instruments for cutting umbilical cord at birth and other unhygienic cord care practices. ${ }^{20}$

In the review by Hendrickse, malaria was responsible for $15 \%, 20 \%$, and $14 \%$ of deaths in the age groups, $0-1,1-5$, and 5-14 respectively. Comparable values of $13.1 \%, 13.1 \%$ and $12.0 \%$ respectively were obtained in this study but there was no death primarily attributable to malaria in the neonatal age group. In contrast, Adeyokunnu et al reported $3 \%$ and $4 \%$ for age group $1-5$ and above 5 years respectively. A probable explanation for this may be the lack of awareness of the possibility of congenital malaria hence, failure to have a blood film examination for malaria parasites in this age group.

Infections such as pneumonia, meningitis and measles and malnutrition remained very important problems among the under 5 . The finding of malignancies (16\%) as the most common cause of death in children above age of 5years was also reported by previous investigators but this proportion represents a slight decrease from the reported $23.8 \%$. Congenital malformations were responsible for $1 \%$ of the overall causes of death. This proportion represents a remarkable decrease compared with the findings of Hendrickse and Adeyokunnu studies. ${ }^{8}$ Adeyemo et $\mathrm{al}^{14}$ studied the contribution of major congenital malformations to morbidity among neonates referred to the University College Hospital, Ibadan, Nigeria over a four year period (1992-1995). Major congenital malformations were found in $11.1 \%$ of 1276 neonatal referrals and ranked fourth among the most common problems in such neonates (after sepsis, jaundice and tetanus but ahead of prematurity and perinatal asphyxia).

Similar to other reports ${ }^{11}$ deaths due to sickle cell anaemia were mainly in children above five years who had various types of crises precipitated by infections including malaria. Majority of the deaths were referred from the secondary health services.

The occurrence of almost half of the deaths in the emergency ward is not surprising because this ward is 
usually the first port of call for most referrals to the hospital, the biggest of all the wards in the department and there was no restriction to admission both day and night hence the high admission and mortality especially in the first two days of admission. In addition, facilities for resuscitation are still grossly inadequate.

This study has further highlighted the fact that majority of childhood deaths in Nigeria are preventable.

\section{References}

1. Black RE, Moris SS and Bryce J. Where and why are 10 million children dying every year? Lancet; $361: 2226$, 2003.

2. Orne-Gliemann J, Perez F, Leroy V, Newell ML, Dabis F. A decade of child health in developing countries. Sante; 13: 69, 2003.

3. Editorial. The world's forgotten children. Lancet; 361 : 9351, 2003.

4. UNICEF. Statistical Tables: Health. Official summary of The State of the World's Children; 12, 2003.

5. Ashely JSA. Present state of statistics from hospital in-patient data and their uses. BrJ Prev Soc Med; 26:

$135,1973$.

6. Kaine W, Okolie J. A review of causes of hospitalisation as guide to the pattern of the diseases in Eastern Nigeria. Nig Med J; 7:205, 1975.

7. Hendrickse RG. Major causes of deaths in infancy and early childhood at the University College Hospital Ibadan. Les Conditions De L'enfant En Milien Rural En Afrique; 123, 1967.

8. Adeyokunnu AA, Taiwo O and Antia AU. Childhood mortality among 22,255 consecutive admissions in the University College Hospital Ibadan. Nig J Paediatr; 7 : 7, 1980.

9. Bamgboye EA, Familusi JB. Mortality pattern at a children's emergency ward, University College Hospital, Ibadan, Nigeria. Afr J Med Med Sci. ; 19:127, 1990.

10. Asindi AA, Ibia EO, Udo JJ. Mortality pattern among Nigerian children in the 1980s. J Trop Med Hyg.94:152, 1991 .

11. Fagbule D and Joiner KT. Pattern of childhood mortality at the University of Ilorin Teaching Hospital. $\mathrm{Nig} J$ Paediatr; 14: 1, 1987.

12. Morley D. Paediatric priorities in the developing world. Apley J, ed. London: Butterworth; 16, 1973.

13. Akindele JA, Oyejide CO, Gbadegeshin RA. Trends in Newborn Mortality over a ten-year period at the University College Hospital, Ibadan, Nigeria. Early Child Dev. \& Care; 80:31, 1992.

14. Adeyemo AA, Gbadegesin RA, Omotade OO. Major congenital malformations among neonatal referrals to a Nigerian university hospital. East Afr Med J;74:699, 1997.

15. English M, Ngama M, Musumba C, Wamola B, Bwika J, Mohammed S, Ahmed M, Mwarumba S, Ouma B, McHugh K, Newton C. Causes and outcome of young infant admissions to a Kenyan district hospital. Arch Dis Child.;88:438, 2003.

16. Lintermans JP. A survey of childhood mortality in a Congolese University Hospital. Env Child Hith.; 18:21, 1972.

17. Obi JO. Analysis of paediatric medical cases admitted to children's clinic, Benin City. Nig Med J.; 6: 69, 1976. 